\title{
Inactivation and Structural Changes of E. Cloacae and B. Subtilis Endospores during IR Laser Water Treatment
}

\author{
S. Ede ${ }^{1}$, L. Hafner ${ }^{2}$, R. Frost ${ }^{3}$ and G. Will ${ }^{*}$
}

${ }^{1}$ Discipline of Energy and Process Engineering, Queensland University of Technology, GPO Box 2434, Brisbane, Australia

${ }^{2}$ School of Biomedical Sciences, Queensland University of Technology, GPO Box 2434, Brisbane, Australia

${ }^{3}$ Discipline of Nanotechnology and Molecular Science, Queensland University of Technology, GPO Box 2434, Brisbane, Australia

\begin{abstract}
The efficiency of $\mathrm{CO}_{2}$ infrared (IR) laser irradiation to disinfect water containing $E$. cloacae and $B$. subtilis endospores was determined and compared to ultraviolet (UV) treatment. Cell viability decreased with IR laser treatment for E. cloacae; however, increased viable cell concentrations were observed in $B$. subtilis endospores. Fourier Transform Infrared (FTIR) spectroscopy and the chemometric method of Principal Component Analysis (PCA) were used to examine cell changes. Increased carbohydrate content was observed in E. cloacae after IR laser treatment.
\end{abstract}

Keywords: Infrared; Water; Micro-organisms; Carbohydrate; FTIR

\section{Introduction}

IR radiation has been studied for micro-organism inactivation of bacterial spores on metal substrates [1] and on metal and paper substrates [2]. A near-point near-infrared laser water treatment apparatus for use in dental hand-pieces was also developed [3]. To date water sterilisation research using a mid-IR laser technique is very rare.

According to the World Health Organisation [4], examinations for faecal indicator bacteria remain the most sensitive and specific way of assessing the hygienic quality of water. Bacteria that fall into this group are E. coli, other coliform bacteria (including E. cloacae) and to a lesser extent, faecal streptococci [5]. Protozoan cysts from organisms which cause giardiasis are the most frequently identified cause of waterborne diseases in developed countries [6,7]. The use of aerobic bacterial endospores to monitor the efficiency of various water treatments has been shown to provide a reliable and simple indicator of overall performance of water treatment $[8,9]$.The efficacy of IR radiation for water disinfection compared to UV treatment has been further investigated in the present study. In addition FTIR spectroscopy in conjunction with Principle Component Analysis was used to characterise structural changes within the bacterial cells and endospores following IR laser treatment. Changes in carbohydrate content of E. cloacae following IR laser treatment were observed.

\section{Materials and Methods}

\section{Bacterial methodology}

E. cloacae (QUT087) was grown on Nutrient Agar (NA) (Oxoid). A lawn inoculation onto sterile NA was created and incubated at $30^{\circ} \mathrm{C}$ for 15 hours. Half of the cells from the incubated NA plates were removed and resuspended in sterile $9.0 \mathrm{~cm}^{3} 0.9 \% \mathrm{NaCl}$ solution and centrifuged (MSE Centaur 2) at $2000 \mathrm{rpm}$ for 10 minutes. The supernatant was discarded and the cells resuspended in $9.0 \mathrm{~cm}^{3}$ of sterile $0.9 \% \mathrm{NaCl}$ solution.

B. subtilis (UQ40) was grown on R2A Agar (Oxoid) by subculturing from an existing culture held in the QUT culture collection. A pure colony grown on R2A was removed and resuspended in sterile $4.5 \mathrm{~cm}^{3}$ $0.9 \% \mathrm{NaCl}$ solution followed by a lawn inoculation onto sterile $\mathrm{R} 2 \mathrm{~A}$ and incubated at $35^{\circ} \mathrm{C}$ for 15 days. Endospores were harvested [10] and the resulting suspension was placed into a water bath at $75^{\circ} \mathrm{C}$ for 15 minutes and then refrigerated at $4 \mathrm{C}$.

The detection of E. cloacae cells and B. subtilis endospores before and during IR and UV experiments was performed by plating onto NA medium and counting by visual identification of the number of viable colonies present.

\section{Reactor configurations}

IR degradation studies were performed using a glass batch reactor (Figure 1A). IR irradiation was provided using a Series $48 \mathrm{CO}_{2}$ laser (Synrad) emitting primarily at $10.6 \mu \mathrm{m}$ with an out-put at full power of $27 \mathrm{~W}$ and applied dose rate of $8.59 \mathrm{~W} \mathrm{~cm}^{-2}$.

UV irradiation studies were performed using a batch reactor configuration (Figure 1B). The source was a low-pressure mercury vapour lamp with an applied dose rate of $5.4 \mathrm{~mW} \mathrm{~cm}^{-2}$.

A volume of $10 \mathrm{~cm}^{3}$ of $18 \mathrm{M} \Omega \mathrm{cm}$ Milli-Q water with $\sim 1.0 \times 10^{\circ}$

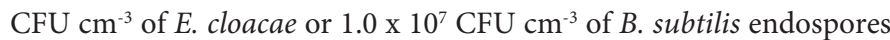
were added to the reaction vessels. IR treatment consisted of repeated cycles of 10 second laser pulses, followed by mixing for 5 seconds. IR irradiation was applied for a total of $0,10,30,60,120,180$ and 270 seconds. UV exposure times were $0,10,3060$, and 120 seconds of continuous irradiation. Immediately after exposure cells were kept in the dark at $4^{\circ} \mathrm{C}$ until detection procedures were performed (no greater than 1 hour).

\section{FTIR and Raman spectroscopy}

FTIR spectra were obtained using a Nicolet 870 Nexus Fourier

*Corresponding author: G. Will, Discipline of Energy and Process Engineering Queensland University of Technology, GPO Box 2434, Brisbane, Australia, Tel. 61731382997; Fax: 6173138; E-mail: g.will@qut.edu.au

Received October 21, 2011; Accepted January 17, 2012; Published January 20 2012

Citation: Ede S, Hafner L, Frost R, Will G (2012) Inactivation and Structural Changes of $E$. Cloacae and $B$. Subtilis Endospores during IR Laser Water Treatment. Hydrol Current Res 3:124. doi:10.4172/2157-7587.1000124

Copyright: (c) 2012 Ede S, et al. This is an open-access article distributed unde the terms of the Creative Commons Attribution License, which permits unrestricted use, distribution, and reproduction in any medium, provided the original author and source are credited. 
Transform IR spectrometer equipped with an ATR objective (Nicolet Instrument Corp., Madison, WI). An Optical Path Difference (OPD) velocity of $0.6329 \mathrm{~cm} \mathrm{~s}^{-1}$ aperture set to 100 , and a gain of 8 was used. A Smart Endurance single reflection ATR accessory with a composite diamond internal reflection element (IRE) with a $0.75 \mathrm{~mm}$ sampling surface and a $\mathrm{ZnSe}$ focusing element was use. Bacterial samples were introduced as $1.0 \mu \mathrm{L}$ samples onto the diamond IRE and allowed air dry for 50 minutes to remove excess water. The spectral range was 4000$525 \mathrm{~cm}^{-1}$ with 128 scans at a $4 \mathrm{~cm}^{-1}$ resolution, and was corrected for the wavelength dependence of the ATR experiment. All spectra were normalised to the amide I band at $1650 \mathrm{~cm}^{-1}$. Spectra were analysed using GRAMS32AI, Galactic Industries Corp., Salem, $\mathrm{NH}$ and chemometric performed using Grams $32 A I$ computer software package with the PSC-IE chemometric add-in (Galactic industries, Salem, NH).

\section{Results and Discussion}

\section{Penetration depth of $\mathrm{CO}_{2}$ laser beam into water}

The depth of penetration of IR radiation into the test substrate determines how far into the substrate inactivation effects are expected to occur. According to Lambert-Bouguer law, the calculated absorption depth of $10.6 \mu \mathrm{m} \mathrm{CO}_{2}$ laser radiation in water is $64 \mu \mathrm{m}$, with $90 \%$ of the energy being absorbed by the depth of $\sim 20 \mu \mathrm{m}$.

\section{Inactivation using IR and UV treatment}

Figure $2 \mathrm{~A}$ shows the percentage inactivation of E. cloacae vegetative cells during exposure of the bacterial cells to the IR laser and UV treatment regimes. In both experiments, a similar initial

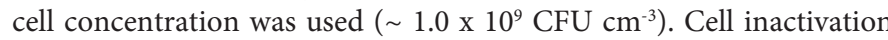
occurred 27 times faster during UV irradiation experiments compared with IR irradiation experiments.

Figure $2 \mathrm{~B}$ shows the inactivation of $B$. subtilis endospores during exposure to the IR laser and UV treatment regimes. While the reduction profile during UV treatment was similar to that of E. cloacae, the cell inactivation rate was slower, due to the increased resistance of the endospores to UV radiation. Despite this, $99.9 \%$ inactivation was attained after two minutes UV exposure. IR exposure did not cause any B. subtilis endospore inactivation and, in fact, resulted in a $270 \%$ increase in cell numbers after 180 seconds of IR exposure.

Both treatment methods follow first order kinetics. Therefore, inactivation rates were calculated using Chick's law [10]. Table 1 displays the inactivation rates for E. cloacae and B. subtilis endospores experiments during IR laser and UV treatment. The IR laser treatment system was found to be less effective than UV irradiation. In comparison to vegetative cells, the UV treatment inactivation rate of endospores

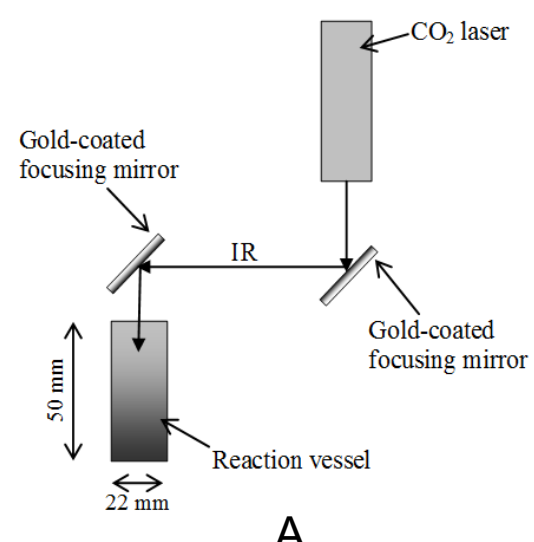

A

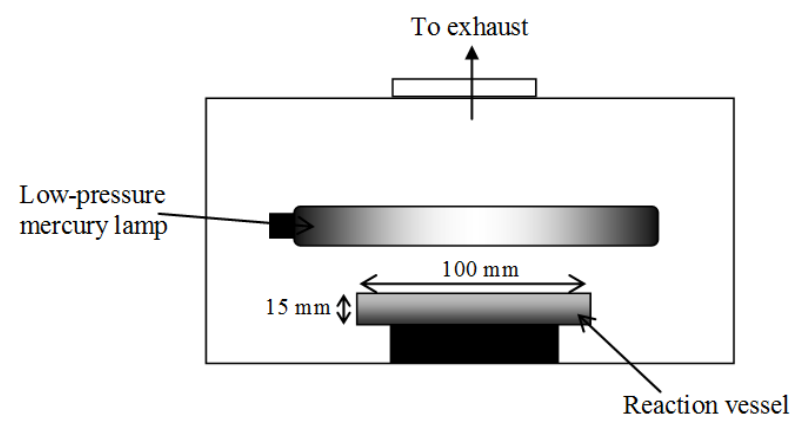

B

Figure 1: Schematic representations of (A) IR; and (B) UV reactor instrumental set-up (not to scale).
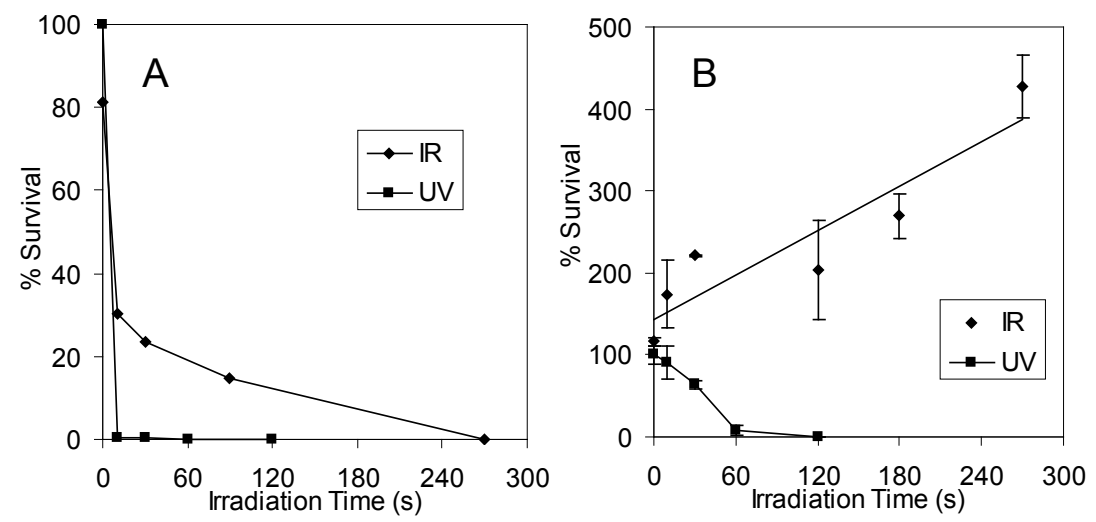

Figure 2: Inactivation of $(A)$ E. cloacae and $(B) B$. subtilis endospores as a function of time during IR laser and UV treatment. 
was approximately $40 \%$ lower than that obtained for vegetative cells, i.e. E. cloacae.

Effect of temperature change during IR treatment: Evidence for heat transfer in the present study is two-fold:

\section{Increase in B. subtilis endospore concentration during IR treatment}

B. subtilis endospores have been shown to germinate upon heat treatment at temperatures greater than $50^{\circ} \mathrm{C}[11,12]$. Overall water sample temperatures increased from $23^{\circ} \mathrm{C}$ to a maximum of $47.5^{\circ} \mathrm{C}$ after 270 seconds of IR laser treatment, with localised boiling of the water surface layer also occurring. This could result in germination of B. subtilis endospores as witnessed by a $400 \%$ increase in endospore numbers after IR laser treatment for 270 seconds. Conversion of endospores into vegetative cells occurs within 30 minutes of germination [13]. Despite samples being kept at $4 \mathrm{C}$ prior to analysis, it is probable that cellular processes were initiated, resulting in the increased viable counts.

\section{Localised heating of the E. cloacae samples}

E. cloacae's optimum temperature range is $30-37^{\circ} \mathrm{C}$ (1984). Therefore, the sudden increase in temperature beyond the optimum for E. cloacae cells most likely resulted in the observed cell death.

FTIR and Raman spectroscopy of bacterial cells and endospores

FTIR spectroscopy has proven a useful technique for investigating cellular changes within micro-organisms. The B. subtilis endospore spectra showed negligible changes after IR treatment. However, significant spectral changes occurred in the E. cloacae cells during IR treatment (Figure 3).
The $v(\mathrm{NH})$ region $\left(\sim 3200 \mathrm{~cm}^{-1}\right)$ denoted as the amide A and the $v(\mathrm{CH})$ region $\left(3000-2800 \mathrm{~cm}^{-1}\right)$ due to fatty acids and methane groups show increased spectral intensity after treatment. Spectral variation within the region $1700-1500 \mathrm{~cm}^{-1}$, dominated by amide vibrations also occurred. These bands are due to $v(\mathrm{C}=\mathrm{O})$ at $\sim 1635-1700 \mathrm{~cm}^{-1}$ denoted as amide I, and $\delta(\mathrm{NH})$ and $v(\mathrm{CN})$ at $\sim 1550-1520 \mathrm{~cm}^{-1}$ denoted as amide II. Assignment by curve fitting of these to protein confirmations revealed that proteins of the sample before treatment primarily consisted of $\beta$-turn and random coil configurations, while after treatment $\alpha$-helices and random coils dominated [14]. A reduction in spectral intensity after IR treatment occurred in the mixed region $\left(1450-1220 \mathrm{~cm}^{-1}\right)$ and is composed of two minor groups of variations: proteins, free amino acids and polysaccharide vibrations (1450-1400 $\left.\mathrm{cm}^{-1}\right)$, and the DNA/ RNA and phospholipid vibrations $\left(1250-1200 \mathrm{~cm}^{-1}\right)$.

The polysaccharide region $\left(1200-900 \mathrm{~cm}^{-1}\right)$ contains the $v(\mathrm{CO})$, $v(\mathrm{CH}), \delta(\mathrm{COH})$ and $\delta(\mathrm{COC})$ modes of vibration and showed the most significant differences during IR treatment. This was of interest as it is in this region that the laser emission will be directly absorbed. The increased carbohydrate content could be a consequence of the breakdown of long chain carbohydrate molecules into shorter chains, or single units, increasing the relative peak intensities within this region. However the optimum temperature range of E. cloacae is 30 $37^{\circ} \mathrm{C}$, and the greatest carbohydrate content was seen in those treated samples whose temperature was brought within this range. At this temperature, bacterial cells have the greatest ability to repair and renew damaged cellular components. It was more likely that the increased carbohydrate content seen within the bacterial samples was due to the repair of damaged carbohydrates and increased production of new carbohydrate molecules.

\begin{tabular}{|c|c|c|c|c|}
\hline \multirow{2}{*}{$\begin{array}{l}\text { Micro-organism } \\
\text { Treatment type }\end{array}$} & \multicolumn{2}{|c|}{ E. cloacae cells } & \multicolumn{2}{|c|}{ B. subtilis endospores } \\
\hline & IR & UV & IR & UV \\
\hline$\%$ Inactivation after $60 \mathrm{~s}$ & 81.83 & 99.99 & -200 & 87.86 \\
\hline Inactivation Rate (CFU cm-3 $\left.\mathrm{s}^{-1} 10^{-3}\right)$ & 25.1 & 100.25 & -4.8 & 61.1 \\
\hline Inactivation Rate (CFU $\left.\mathrm{cm}^{-3} \mathrm{~kJ}^{-1}\right)$ & 0.0154 & 4.03 & -0.00296 & 2.40 \\
\hline $\mathrm{R}^{2}$ & 0.972 & 0.865 & 0.995 & 0.959 \\
\hline
\end{tabular}

Table 1: Inactivation rates for E. cloacae cells and $B$. subtilis endospores treated with IR laser and UV treatment.

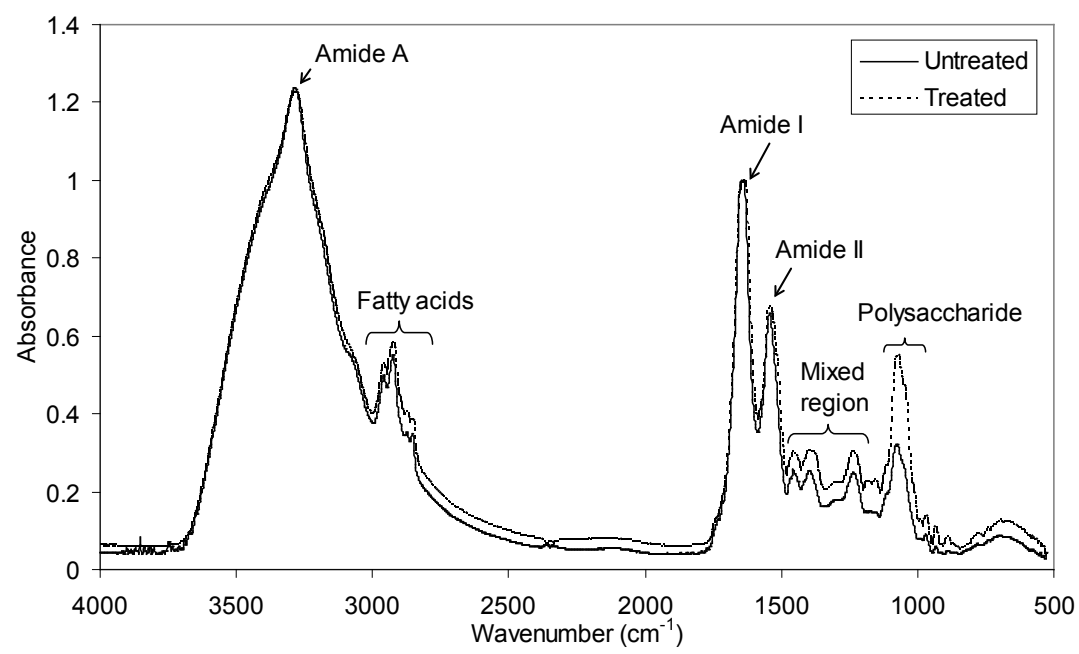

Figure 3: FTIR-ATR-corrected, normalised (to Amide I band at $1640 \mathrm{~cm}^{-1}$ ) absorbance spectra of $E$. cloacae before and after IR laser treatment for $30 \mathrm{~s}$. 

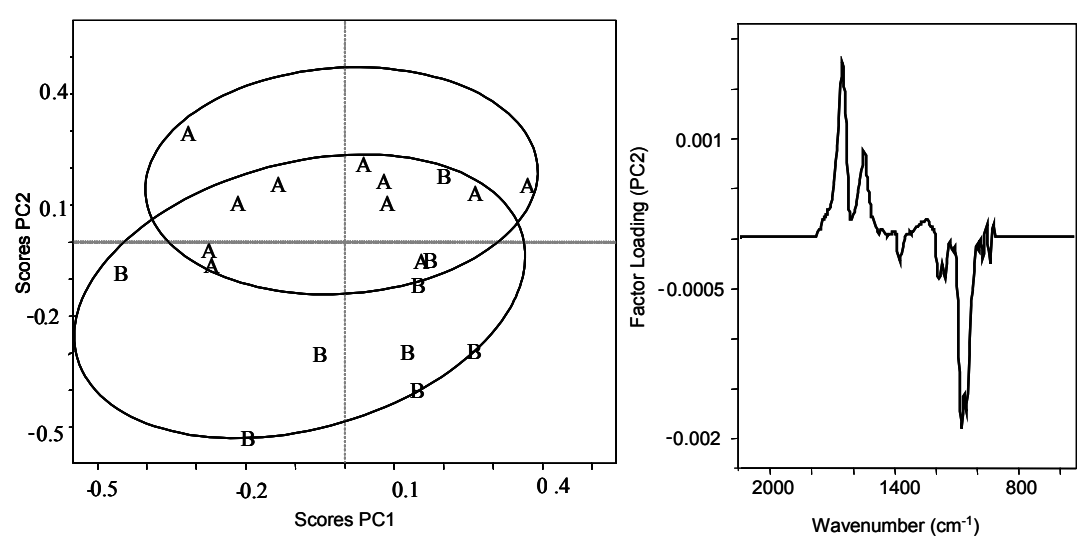

Figure 4: PC1 vs PC2 scores and loadings plots of E. cloacae IR treatment spectral data set from $1760-850 \mathrm{~cm}^{-1}$.

Chemometric Principal Component Analysis (PCA) was applied to the FTIR-ATR spectra obtained for both E. cloacae and B. subtilis endospores using the IR laser and UV treatment regimes. The only experimental data set which showed cluster separation was the IR laser treated E. cloacae samples; however, cluster overlap was still seen. The entire spectral region was investigated, but it was the region from $1760-850 \mathrm{~cm}^{-1}$ that showed separation (Figure 4). Here, the before and after samples were separated by the PC 2 axis, predominately governed by positive factor loadings peaks at $1625 \mathrm{~cm}^{-1}$ (amide I), $1520 \mathrm{~cm}^{-1}$ (amide II) and $1240 \mathrm{~cm}^{-1}$ (phosphodiesters). Negative peaks at 1060 $\mathrm{cm}^{-1}$ (carbohydrate) indicated that untreated samples contained more protein, due to the increased amide I and II intensities, and that treated samples possessed a higher carbohydrate content than their untreated counterparts [15].

\section{Conclusions}

$\mathrm{CO}_{2}$ laser irradiation was investigated for inactivation efficiency, and compared to that of UV irradiation, of E. cloacae and B. subtilis endospores. E. cloacae inactivation was achieved using IR laser treatment; however, this was most likely due to thermal heating of the sample. The more resistant $B$. subtilis endospores were not inactivated using IR laser treatment.

FTIR-ATR spectroscopy exposed dramatic increases in the polysaccharide content of the E. cloacae. Chemometric analysis applied to the FTIR-ATR spectra showed cluster separation for the IR laser treated E. cloacae samples indicating cellular changes occurred during the IR laser treatment. The changes identified using chemometric analysis were a decrease in protein content and an increase in total polysaccharide. As the IR laser used emitted within the polysaccharide region it was possible that these molecules within the bacterial cell absorbed sufficient energy to be damaged, which in turn could cause the cell to replace or repair the lost polysaccharides.

Although inactivation after exposure of E. cloacae to IR irradiation did occur, the IR laser treatment method failed to inactivate resistant micro-organisms, i.e. B. subtilis endospores, and may limit its utility for water disinfection purposes.

\section{Acknowledgements}

The authors would like to thank Cooper S. at the University of Queensland,
School of Physics for use of the $\mathrm{CO}_{2}$ laser. Ede, SM. would like to thank the CIDC and Inorganic materials research program for funding throughout this research.

\section{References}

1. Molin G, Ostilund K (1975) Dry-heat inactivation of Bacillus subtilis spores by means of infra-red heating. Antonie van Leeuwenhoek 41: 329-335.

2. Pratt GW Jr (1976) Method of altering biological and chemical activity of molecular species. (Massachusetts Institute of Technology, USA).

3. Baca AM (2002) Near point of use laser water treatment systems and methods US Pat Appl Publ USA, (USA).

4. WHO (1993) Guidelines for Drinking Water Quality, 2nd edn, Vol 1 Geneva World Health Organisation.

5. Mara D, Horan N (2003) Handbook of water and wastewater microbiology. London, Academic Press.

6. Craun GF, Hubbs SA, Frost R, Calderon RL, Via SH (1998) Waterborne outbreaks of Cryptosporidiosis. J Am Water Works Assoc 90: 81-91.

7. Betancourt WQ, Rose JB (2004) Drinking water treatment processes for removal of Cryptosporidium and Giardia. Vet Parasitol 126: 219-234.

8. Coallier J (1996) Full-scale physical and chemical removals of a fast response and economic microbiological indicator. WQTC Proceedings, Boston, MA, American Water Works Association.

9. Rice EW, Fox KR, Miltner RJ, Lytle DA, Johnson CH (1996) Evaluating plant performance with endospores. J Am Water Works Assoc 88: 122-130.

10. Haas CN, Kaymak B (2003) Effect of initial microbial density on inactivation of Giardia muris by ozone. Water Res 37: 2980-2988.

11. Alimova A, Katz A, Gottlieb P, Alfano RR (2006) Proteins and dipicolinic acid released during heat shock activation of Bacillus subtilis spores probed by optical spectroscopy. Appl Opt 45: 445-450.

12. Daniels JK, Caldwell TP, Christensen KA, Chumanov G (2006) Monitoring the kinetics of Bacillus subtilis endospore germination via surface-enhanced raman scattering spectroscopy. Anal Chem 78: 1724-1729.

13. Ricca E, Henriques AO, Cutting SM (2004) Bacterial spore formers: probiotics and emerging applications. Wymondham, Horizon Bioscience.

14. Parker FS (1983) Applications of infrared, raman, and resonance raman spectroscopy in biochemistry.

15. Brandenburg K, Seydel U (2002) Vibrational spectroscopy of carbohydrates and glycoconjugates. Handbook of Vlbrational Spectroscopy.

16. Facile N, Benoit B (2000) Evaluating bacterial aerobic spores as a surrogate fo Giardia and Cryptosporidium inactivation by ozone. Water Res 34: 3238-3246.

17. Krieg N, Holt J, Eds. (1984) Bergey's Manual of Systematic Bacteriology. Baltimore, MD, Williams and Wilkins. 